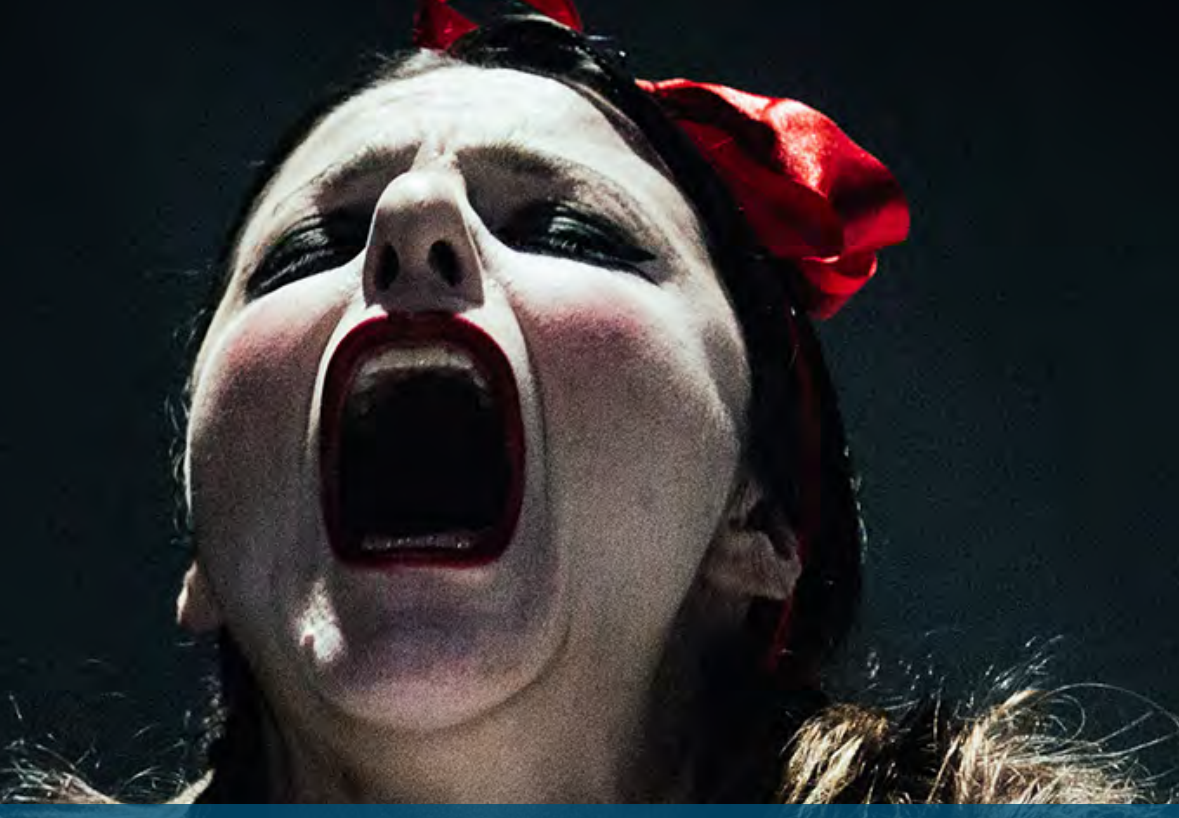

\title{
A biografia cultural de uma camisa: a memória trajada de Antoninha Berchon Sampaio
}

Cultural biography of a shirt: the dressed memory of Antoninha Berchon Sampaio

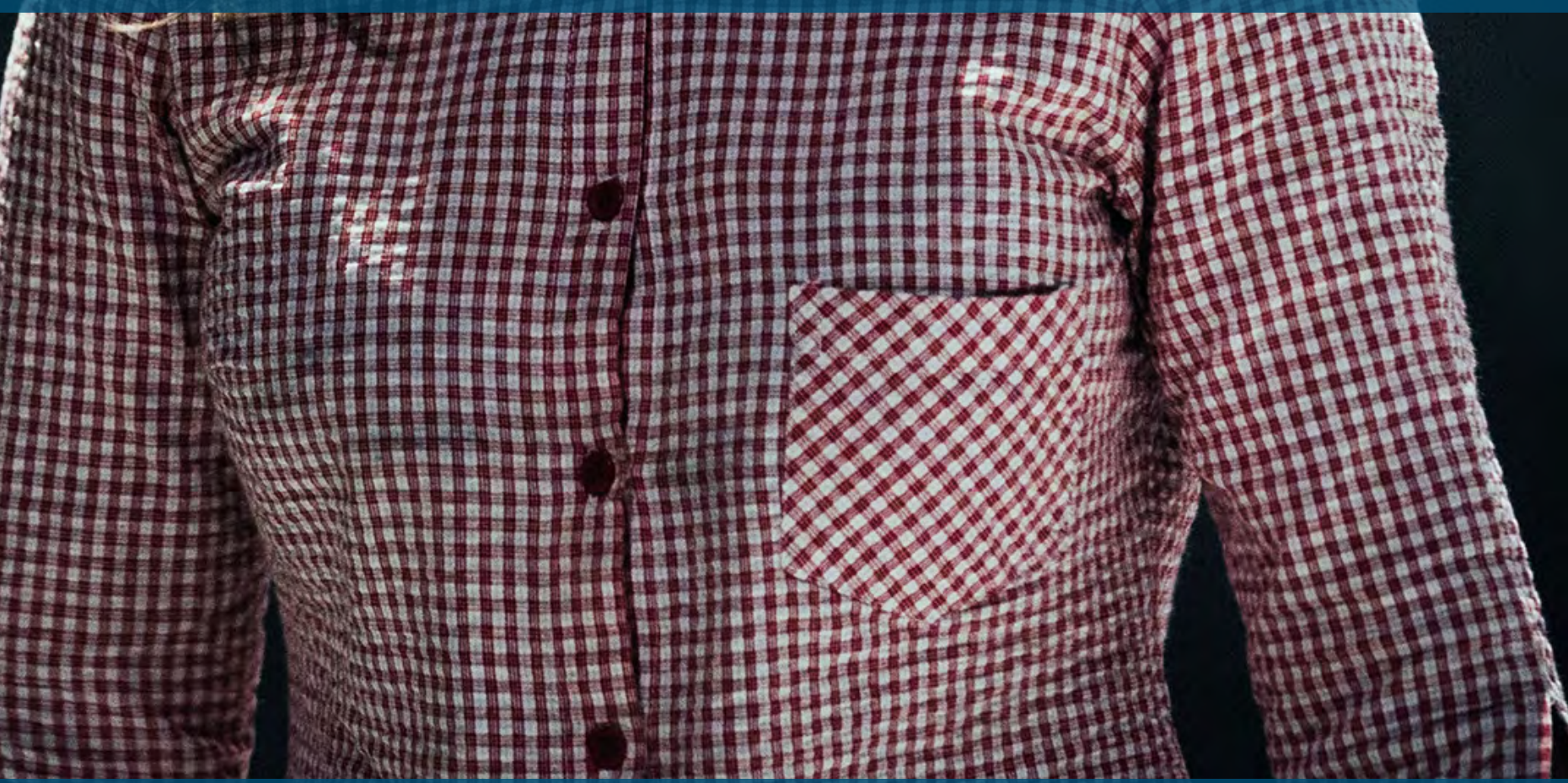




\section{FRANTIESKA HUSZAR SCHNEID ${ }^{1}$}

ORCID: https://orcid.org/0000-0002-9351-0776

\section{RAPHAEL CASTANHEIRA SCHOLL 2}

ORCID: https://orcid.org/0000-0001-7161-2715

[resumo] 0 artigo busca destacar uma peça de vestuário do acervo que pertenceu à Sra. Antoninha Berchon Sampaio, uma figura relevante na sociedade de elite do Rio Grande do Sul. Esta peça e todas as outras que compuseram o acervo, serviram de aporte para o projeto "Memória Trajada", que se propôs a pesquisar o traje como objeto cultural a partir dos pressupostos de Prown (1982), Andrade (2006; 2008) e Gies (2008). 0 objetivo geral do estudo foi pesquisar uma camisa de Antoninha Berchon, abordando questões relacionadas aos arquivos pessoais (ARTIÈRES, 1998; BELLOTO, 2006; VIDAL, 2007; CUNHA, 2008), interligando estes a temas que tratam da moda e seus elos com a memória e a cultura material. Justifica-se a escolha de tal pesquisa por entender as diversas possibilidades metodológicas da roupa como um artefato cultural e da circulação do traje por meio de diferentes sujeitos em seus corpos, imagens e espaços. A metodologia utilizada nesta pesquisa teve como base o estudo de Andrade (2006; 2008) sobre artefatos têxteis, porém adaptado ao acervo analisado. Almejou-se a construção de uma tessitura interdisciplinar, na qual se entrelaçaram diversos campos do saber e estes são fundamentais para entender as mensagens que os artefatos contam. Assim sendo, pode-se afirmar a importância da relação da roupa como objeto que carrega e narra memórias.

\section{[palavras-chave] Acervo de vestuário. Memória trajada. Cultura material.}

\footnotetext{
1 Mestre e doutoranda em Memória Social e Patrimônio Cultural pelo Programa de Pós-Graduação em Memória Social e Patrimônio Cultural da Universidade Federal de Pelotas. Docente do curso de Design de Moda do Instituto Federal Sul-rio-grandense. E-mail: frantieskahs@gmail.com. Lattes: http:// lattes.cnpq.br/2346887754842567.

2 Doutor em Educação pelo Programa de Pós-Graduação em Educação da Pontifícia Universidade Católica do Rio Grande do Sul. Docente do curso de Design de Moda do Instituto Federal Sul-rio-grandense. E-mail: raphasholl@gmail.com. Lattes: http://lattes.cnpq.br/1162131987927410.
} 
[abstract] This paper aims to highlight a piece of the clothing collection which belonged to Mrs. Antonia Berchon Sampaio, a relevant figure in the elite society of Rio Grande do Sul. The collection in question is composed of pieces of clothing that made up the personal wardrobe of Mrs. Berchon. This piece and all the others that composed the collection served as a contribution to the "Dressed Memory" project, which had the purpose of researching costume as a cultural object based on the contributions of Prown (1982), Andrade (2006; 2008), and Gies (2008). The overall objective of the study was to investigate a shirt which belonged to Antoninha Berchon, addressing issues related to personal files (ARTIÈRES, 1998; BELLOTO, 2006; VIDAL, 2007; CUNHA, 2008), and linking these with fashion and its connections with memory and material culture. The choice of this research is justified since it is possible to understand the various methodological possibilities of clothing as a cultural artifact and the circulation of the costume through different subjects in their bodies, images, and spaces. The methodology used in this research was based on the study of Andrade $(2006 ; 2008)$ on textile artifacts but adapted to the analyzed acquis. The objective was to build an interdisciplinary tessitura, intertwining several fields of knowledge; these are fundamental to understand the messages spoken by the artifacts. Therefore, it is possible to reassure the importance of the relationship of clothing as an object that carries and narrates memories.

[keywords] Clothing collection. Dressed memory. Material culture.

Recebido em: 14-03-2019.

Aprovado em: 23-04-2019. 


\section{Introdução}

A pesquisa apresentada nesse artigo é resultado parcial do projeto de pesquisa "Memória Trajada", que estuda o acervo de Antoninha Berchon Sampaio e suas relações com a memória. Para o presente trabalho, fez-se uma análise da biografia cultural de uma camisa, peça esta que habitou o guarda-roupa desta senhora, considerada agente do patrimônio cultural do Rio Grande do Sul ${ }^{3}$. Antoninha não é o objeto de pesquisa do presente estudo, porém é imprescindível saber mais do corpo e alma que habitou em primeira mão a camisa.

0 estudo pretende provocar reflexões resultantes da costura entre moda, memória, acervo e biografia cultural. Tais considerações só são permitidas se alinhavadas com apontamentos da cultura material (PROWN, 1982; MENESES, 1998; GLASSIE, 1999; MILLER, 2005; ANDRADE 2011; GIES, 2013). Para compreender as relações entre moda e memória, a pesquisa buscou apoiar-se em estudos já existentes que apresentaram inter-relações entre ambos os temas, esclarecendo o caráter interdisciplinar que se estabelece nos trabalhos que versam acerca da moda e seus múltiplos caminhos, sejam eles históricos, sociológicos, econômicos, antropológicos, estéticos, psicológicos, e outros tantos atributos que resultam em diversas variáveis para compreensão da moda para além do seu cunho material.

Foram priorizados dois procedimentos metodológicos para a construção da pesquisa. Primeiro, foi realizada uma revisão bibliográfica acerca dos temas e, em seguida, foi aplicado o procedimento metodológico de caráter prático (PROWN, 1982; ANDRADE, 2008) para o desenvolvimento da análise de uma peça do acervo de vestuário da personagem em questão.

Desta forma, o texto foi organizado da seguinte forma: primeiro, é feita uma revisão bibliográfica sobre as relações de moda com memória, utilizando Stalybrass (2012), Perrot (1989), Simili (2012) e Benarush (2012; 2014; 2015); logo após, é realizado um estudo da roupa pelo viés da cultura material, baseando-se em Prown (1982), Meneses (1983; 1998), Taylor (2004), Andrade (2006; 2008; 2011; 2016), Gies (2008; 2013) e Miller (2013); para então, chegar na biografia cultural ${ }^{4}$ da camisa analisada, fundamentada nos estudos de Andrade $(2006 ; 2008 ; 2011 ; 2016)$ e Kopytoff $(2008)^{5}$.

As referências bibliográficas utilizadas auxiliaram na reflexão da roupa como documento histórico e objeto ${ }^{6}$, em um contexto cultural. A escolha dos autores de diversas áreas se deu com o intuito de experimentar as potencialidades dos objetos por uma visão interdisciplinar.

\footnotetext{
"Antoninha Sampaio também foi importante colaboradora da valorização do patrimônio e da cena cultural de Pelotas. Contribuiu para o tombamento de prédios no entorno da Praça Coronel Pedro Osório e do Teatro Sete de Abril, além da consolidação do Museu da Baronesa" (FARAC0, 2014).

${ }^{4}$ Os conceitos de biografia cultural são apresentados através de autores e aplicados na seção "Biografia cultural da camisa".

As obras dos referidos autores são analisadas e discutidas ao longo da revisão bibliográfica.

No estudo optou-se pela conceituação a partir do termo objeto (MENESES, 1998), ainda que sejam possíveis outras abordagens, como artefato, trecos, troços, coisas, restos, rastros, vestígios, relíquias, quinquilharias etc.
} 
O projeto de pesquisa "Memória Trajada"7 tem a finalidade de identificar, descrever e analisar o acervo de vestuário de Antonia Berchon des Essarts Carvalho de Oliveira Sampaio, conhecida como Antoninha Berchon. A intenção da pesquisa é levantar questões em torno da memória e suas relações, mais precisamente sobre o vestuário de Antoninha Berchon, como este representa e conta histórias de sua trajetória. Além das roupas, a presente pesquisa utiliza fotografias da personagem vestindo as peças estudadas.

A personagem citada no estudo faleceu em 2014, aos 96 anos, sendo ainda, nos dias atuais, considerada uma figura representativa para a memória de Pelotas pela defesa do patrimônio cultural da cidade. Os pertences de Antoninha Berchon permaneceram, durante três anos, no apartamento onde ela morava, até as filhas decidirem o que seria feito com o acervo $^{8}$ da mãe. Calligaris explica que este acervo se transforma em arquivo pessoal, mesmo sem a intenção por parte do portador ainda em vida. E cabe aos filhos separar e dar o destino para os objetos que acompanharam os pais durante toda a vida,

[...] desde as fotos de lembrança até a simples acumulação de objetos e documentos [...]. Esses conjuntos, às vezes confusos, outras vezes ordenados e organizados, reunidos ou não com o intento de construir um arquivo, se transformam inevitavelmente em arquivos pessoais (autobiografias materiais, por assim dizer), pela morte do sujeito que os acumulou. Assim, no mínimo uma vez na vida, cada um torna-se arquivista, quando se depara infelizmente com a necessidade de esvaziar a casa de seus pais depois da morte deles (CALLIGARIS, 1998, p. 46).

Em 2017, a família doou o acervo da senhora para a Associação dos Amigos da Baronesa (Ambar), entidade da qual dona Antoninha foi considerada presidente de honra. A Ambar fez um contato com uma das pesquisadoras, convidando para avaliar as peças que compunham o acervo. A partir deste contato inicial, surgiu a idealização da pesquisa e a ideia de criar um brechó para comercializar as peças e reverter a quantia arrecadada para melhorias no Museu da Baronesa. Além de angariar verbas, a ideia era que as peças que acompanharam dona Antoninha passassem a habitar outros corpos e vivessem outras histórias, premissas essas que dariam início ao projeto "Memória Trajada" e norteariam as pesquisas decorrentes. Assim, utilizou-se a proposição de Andrade (2008, p. 30) de que: "fora do corpo e do guarda-roupa que um dia a abrigou, aquele vestido passará por novos estados, se conectará a outros espaços e estará sujeito à novas interpretações". Desse modo, no estudo verificou-se a circulação de um objeto-vestuário em sua trajetória de uso pela primeira proprietária e seus outros caminhos.

O objetivo geral do projeto é pesquisar o acervo de vestuário de Antoninha Berchon, abordando questões relacionadas aos arquivos pessoais (ARTIÈRES, 1998; BELLOTO, 2006;

\footnotetext{
7 Termo utilizado por Michelle Perrot (1989) no artigo "As práticas na memória feminina".

8 Termo utilizado pelos familiares para se referirem ao conjunto de objetos de Antoninha.
} 
VIDAL, 2007; CUNHA, 2008), nas pesquisas de caráter científico que tratem da moda e seus elos com a memória e a cultura material. A metodologia utilizada nesta pesquisa teve como base o estudo de Andrade (2006) sobre artefatos têxteis, porém adaptado para o acervo analisado aqui. A metodologia contempla as seguintes etapas:

1. higienização: o acervo encontrava-se guardado em um apartamento desocupado (local onde morava Antoninha Berchon) e precisava ser higienizado, de acordo com as normas de conservação, para que não houvesse nenhuma perda das características originais dos objetos;

2. inventário: inicialmente foi feito um levantamento de todo o acervo - roupas e acessórios. A quantidade foi totalizada em 326 peças, sendo 229 peças de roupas e 97 de acessórios. Dentre estas peças, nem todas pertenciam à figura citada, mas à família Berchon Sampaio ${ }^{9}$. Deste total, foram selecionadas 25 peças de roupas como objetos de estudo do projeto "Memória Trajada". A seleção destas peças contou com a participação de uma das filhas da senhora Antoninha Berchon, que identificou quais peças seriam pesquisadas, em concordância com os critérios estabelecidos pelos pesquisadores, a saber: peças identificadas com etiqueta/ marca, trajes que estivessem demarcados por importância do seu uso (acontecimentos, ocasiões, fatos), técnicas de confecção (trajes feitos sob medida e/ou com técnicas de costura raras ${ }^{10}$ ) e roupas identificadas em fotografias;

3. identificação: fichas de sistematização foram criadas para que se extraísse a maior quantidade de informações sobre as peças. Fita métrica e máquina fotográfica auxiliaram nesta etapa de reconhecimento dos objetos. Para a construção das fichas, utilizou-se: Frings (2012) para as categorias do vestuário e faixas de preços e estilos; Benarush (2014), que organizou a obra Termos básicos para catalogação de vestuário ${ }^{11}$ e Faerm (2012) para descrição das peças e componentes da roupa como golas, colarinhos, mangas, punhos e demais informações. Neste momento, também foram criados os desenhos técnicos para que as impressões pessoais dos pesquisadores pudessem ser compartilhadas, além de questionadas, caso os objetos não estivessem mais disponíveis para um exame minucioso, como indicado por Prown (1982);

4. pesquisa em outras fontes e programas de pesquisa: avançou-se para a leitura e uso de fontes escritas e iconográficas, externas aos objetos estudados, com a finalidade de comparação. A pesquisa bibliográfica e iconográfica serve para esclarecer uma série de questões como, por exemplo, qual a data aproximada da roupa, como

\footnotetext{
${ }^{9}$ As peças que formavam o acervo da família Berchon Sampaio não eram compostas por peças herdadas, mas sim por trajes que pertenceram a diversos membros da família.

${ }^{10}$ Exemplo disto é um traje assinado por Walter Otegui, no qual havia moedas presas na parte interna da bainha do vestido, para dar o caimento necessário à peça.

${ }^{11}$ Uma adaptação do Vocabulary of Basic Terms for Cataloguing Costume do ICOM (Internacional Committe for Museums and Collection of Costume).
} 
estas peças eram usadas, se o desenho (tecidos, aviamentos, silhueta, detalhes) era caraterístico do período. Ainda nesta etapa, uma análise do contexto de consumo da tendência de moda foi realizada, com auxílio da foto da usuária portando o traje;

5. brechó: após as peças higienizadas, observadas, descritas, identificadas, exploradas e pesquisadas, foi organizado um brechó que comercializou 278 peças e toda a verba arrecadada foi destinada para reformas e melhorias no Museu da Baronesa;

6. divulgação do projeto: foi criado um perfil no Instagram (@memoriatrajada) para compartilhar o andamento da pesquisa, que durante esta etapa, possibilitou experiência para duas alunas bolsistas e quatro voluntárias ${ }^{12}$ nas áreas de produção de moda, marketing de moda e história da moda. Através do trabalho dos pesquisadores e alunos envolvidos, foi realizado um editorial de moda para demonstrar novas maneiras de uso das roupas.

\section{Roupa e suas múltiplas relações com a memória}

Vestuário e moda podem ser analisados a partir de uma visão multidisciplinar/interdisciplinar, por pesquisadores oriundos de diversos campos do conhecimento. Benarush reforça atestando que:

O estudo da moda como fenômeno cultural, multidisciplinar por natureza, instiga investigações teóricas nos diversos campos do saber. Estudos da história, sociologia, psicologia, filosofia e economia, já considerados clássicos, ajudaram a consolidar a moda no universo acadêmico (BENARUSH, 2012, p. 114).

Assim sendo, afirma-se que diversas áreas discutem a questão da moda e a relacionam com a memória, o indivíduo e a roupa, atestando que esta intersecção pode se tornar um objeto de estudo. Andrzejewski (2015, p. 89) fala desta relação: “[...] percebemos que a roupa, como objeto de estudo para a memória social, responderá questões por ter em comum os pontos de deflagrações dessas memórias". Desse modo, compreende-se que a roupa, enquanto objeto de investigação, não abrange em si todas as possibilidades e questionamentos, pois ela dependerá de outros fatores externos à sua materialidade.

Por esse ponto de vista, pode-se inserir e explorar a vestimenta como um documento social; compreende-se que as roupas e acessórios podem dizer sobre o modo de vida dos sujeitos, pois documentam a passagem destes no tempo e constituem-se como fontes de conhecimento sobre estética, costumes e hábitos de determinados períodos.

Simili (2012, p. 3) aborda que "as roupas são marcadores da memória sentimental". Já Pollack (1992, p. 2) diz que “a memória é constituída por pessoas, personagens”. E, assim

\footnotetext{
${ }^{12}$ Curso Técnico em Vestuário e Tecnólogo em Design de Moda do Instituto Federal Sul-rio-grandense.
} 
sendo, juntos, o indivíduo e a roupa assumem atribuição de personagens dessa trama, pois ao passar pelos acontecimentos, tornam-se peças-chave para a sua relação com a memória. Isto posto, pode-se pensar a moda como dispositivo para memórias de acontecimentos vividos, sendo a roupa uma maneira palpável de interpretar episódios marcantes no imaginário de uma sociedade.

É como se a roupa fosse um elo entre presente e passado, perpassando pela utilidade da vestimenta. Schmitt (2009, p. 2), na resenha do livro O casaco de Marx: roupas, memória, dor (STALLYBRAS, 2012), ao falar das vestimentas, afirma que "além de representarem a presença física e rememorarem, a todo instante, a ausência de quem partiu, denotam também as escolhas pessoais, seus gostos e opiniões: são verdadeiras relíquias". A relíquia possui a capacidade de evocar memórias, sendo um agente de lembrança, ou funcionando como vestígio do indivíduo que já se foi, como é o caso da jaqueta de Allon. Uma roupa também pode representar a ausência de alguém "eternizando uma prova palpável da existência daquele sujeito histórico" (MACIEL, 2013, p. 20).

Neste sentido, o objeto-vestuário pode ser compreendido, de acordo com Perrot (1989), como uma relíquia. Para a autora, um vestido, um lenço, um chapéu, a cor de uma echarpe, representam para as mulheres um acontecimento, uma sensibilidade de valor único evocada através da roupa. Perrot (1989, p. 15) afirma que "a memória das mulheres é uma memória trajada". Nessa perspectiva, então, afirma-se que as roupas são instrumentos da memória, por meio das quais o indivíduo recorda suas passagens por momentos que marcam sua história.

A moda, através das roupas, é o elemento mais próximo das pessoas. Por intermédio do vestuário - roupas e acessórios - rememora-se com detalhes ocasiões marcantes que se apresentam conectadas a acontecimentos da trajetória pessoal de cada indivíduo. Benarush (2012, p. 116) diz que "As roupas mostram muito mais do que somente formas, volumes, cores e texturas: nas roupas é possível também ver o envolvimento emocional, corporal e sensorial das pessoas que as usaram". Porém, é necessário investigar sobre quem produziu, quem e em que período vestiu, se foi desprezado, descartado ou guardado, entre outros aspectos. Benarush aborda sobre narrativas que surgem através das biografias das roupas:

As histórias que as roupas contam são dos costumes, das maneiras, dos relacionamentos, das regras sociais. Mas também são histórias de tecnologia, de manufatura, de gosto, de tradições. As roupas têm esse poder, de guardar as curvas de quem as usou, o puído, a memória (BENARUSH, 2015, p. 100-101).

Ao abordar o assunto memória a partir das roupas, Stallybrass (2012, p. 13-14) afirma que a vida social da roupa "está no fato de que ela nos recebe, recebe nosso cheiro, nosso suor, recebe até mesmo nossa forma. [...] As roupas recebem a marca humana”. E Andrade vai além, fala de outros caminhos que as roupas podem tomar: "Fora do corpo e do guarda-roupa que um dia a abrigou, aquela roupa viverá uma outra vida, se conectará a outros corpos e estará sujeita a novas interpretações" (ANDRADE, 2006, p. 5). 
Stallybras (2012, p. 11) diz que a roupa está intrinsecamente ligada à memória. 0 autor afirma que "os corpos vêm, e vão: as roupas que receberam esses corpos sobrevivem". É possível pensar no corpo como algo que preenche a roupa, pois, quando a vida acaba, as roupas ficam lá, nos mesmos cabides dentro do armário, carregando seu cheiro, contando sua história. As roupas também não duram para sempre, porém elas estendem a presença, a essência e atestam a personalidade de quem as usou. A partir do conceito de mútua constituição de Miller (2013, p. 37), pode-se pensar que é necessário investigar detalhadamente as roupas não apenas como representação de sujeitos, mas como elementos que compõem, organizam e arranjam quem as utiliza.

Uma peça de roupa, analisada como memória, é aquela que aciona conexões nos sujeitos e reminiscências de tempos, atestando não apenas a constituição de uma peça, mas também a construção social que nela se instaura.

As roupas são, por natureza, frágeis e sujeitas a um tempo relativamente curto, devido ao uso, lavagens e ajustes, ou seja, as roupas são objetos temporais, principalmente quando a roupa se relaciona com a moda. As características físicas das fibras, aliadas com a forma de pertencimento pelos seus usuários e o mundo externo, fazem com que poucas sobrevivam com o tempo. Paula corrobora isso, afirmando que "Os tecidos são materiais especialmente frágeis e suscetíveis à deterioração” (PAULA, 2006, p. 266). Por isso, neste estudo optou-se por usar a roupa como fonte principal, e a fotografia como fonte auxiliar para a análise das formas vestimentares ${ }^{13}$. Nacif explica a importância e, ao mesmo tempo, as dificuldades de trabalhar com fotografia nos estudos de moda:

\footnotetext{
A imagem é tradicionalmente uma fonte privilegiada para o estudo das formas vestimentares [...] representada, proporcionando informações que, somadas às outras fontes tradicionais (escritas ou o objeto traje) contemplam aspectos muito diversos e enriquecedores. Mais recentemente, a fotografia passou a constituir um tipo de imagem importante para se conhecer as formas vestimentares contemporâneas [...] (NACIF, 2007, p. 5).
}

A indumentária e a moda passam a ser pontos de referência significativos para análise de uma época ou situação vivida, para se entender os usos, costumes e mudanças, criações e recriações que ficaram congeladas na imagem fotográfica. Além disso, trazem a oportunidade de relembrar aquele momento; as imagens ancoram-se nos elementos presentes da cena retratada, bem como possibilitam se apoiar no documento histórico para também não se deixar esquecer e ajudar a compor o lembrar.

\footnotetext{
13 “Optei por empregar o termo 'formas vestimentares' para me referir às práticas encontradas neste estudo, o qual foi tomado de empréstimo de Denise Pop-Câmpeanu - mestre de conferências na École de Hautes Études em Sciences Sociales (EHESS) nos anos 1990. [...] Mais do que refletir a moda de um período, o aspecto e ordenação destas formas vestimentares, constituem a expressão individual e as escolhas simbólicas de um grupo" (VOLPI, 2018, p. 14).
} 


\section{0 estudo da roupa pelo viés da cultura material}

0 termo cultura material relaciona-se aos objetos, ao corpo material e às estruturas produzidas por uma certa sociedade. Para Miller (2013, p. 7), "A cultura material prospera como substituta indisciplinada de uma disciplina: é inclusiva, abrangente, original, às vezes com pesquisas e observações peculiares". Os estudos da cultura material não servem apenas para perceber como determinados valores são atribuídos aos objetos mas, sobretudo, compreender também como essas materialidades agem sobre os sujeitos.

De acordo com Glassie (1999), o estudo da cultura material usa objetos para abordar o pensamento humano em ação. Tal estudo provê uma abordagem acadêmica multidisciplinar para a análise de diversos tipos de objetos, possibilitando expandir ou adicionar ao corpo de conhecimento já existente (GIES, 2013). Miller (2005) corrobora, afirmando que a cultura material não é um estudo ancorado apenas na etnografia, mas eclético em seus métodos e abordagens das múltiplas disciplinas e suas contribuições. A cultura material é considerada uma nova tecnologia na área de investigação (MILLER, 2005). Para Attfield (200014 apud GIES, 2008, p. 3), "o que começou como um pequeno desdobramento tem se desenvolvido consideravelmente, e que é esperado que esse crescimento continue e floresça”.

Na cultura material, a fonte de conhecimento é o próprio objeto, não sua representação imagética ou descrição textual: “[...] os objetos figuram como uma espécie de eixo permanente e ponto de partida das pesquisas" (JULIÃO, 2006, p. 95). Ao analisar um objeto, pode-se obter indícios da tecnologia de manufatura, dos materiais utilizados na sua construção, formas, cores e detalhes. A cultura material é também um processo de descoberta, por meio dos objetos, dos valores simbólicos, sociais, materiais, imateriais, entre outras tantas valorações que se possa atribuir a quem os fez ou os usou (PROWN, 1982; SCHIFFER, 1999). Volpi (2014) ainda complementa que, a partir deles, pode-se compreender quais são os valores significativos em nível cultural e estético empregados em cada artefato.

A leitura do objeto se dá em diversos níveis, do abstrato ao material, do mundo visível ao invisível. Segundo Bourdieu (1983), a relação entre objetos e a mente é que estes são o resultado tangível de como a mente trabalha. E nesta perspectiva, pode-se relacionar com os conceitos de Pomian, para quem o objeto tem potencial de passar de utilitário para semióforo, ou seja, objetos "que representam o invisível, são dotados de um significado; não sendo manipulados, mas expostos ao olhar, não sofrem usura” (POMIAN, 1984, p. 71). Meneses também aborda esta categoria de objetos: "Relíquias, semióforo, objetos históricos: seus compromissos são essencialmente com o presente, pois é no presente que eles são produzidos ou reproduzidos como categoria de objeto e às necessidades do presente que eles respondem" (MENESES, 1998, p. 94).

Os objetos podem ser entendidos como fontes para contar histórias e memórias e, no caso do referente estudo, o objeto-vestuário é visto como um documento dentro da metodologia de pesquisa, assim como qualquer fonte tradicional. Andrade afirma que:

${ }^{14}$ ATTFIELD, Judy. Wild Things: the material culture of everyday life. Oxford: Berg, 2000. 


\begin{abstract}
Priorizar a própria roupa como fonte histórica dentro de um trabalho de pesquisa é reconhecer, finalmente, o papel fundamental e central desta fonte na história e no cotidiano da moda. A reflexão a respeito do riquíssimo valor histórico que está naquilo que vestimos é um excelente caminho no estudo e na preservação do nosso patrimônio cultural através da moda (ANDRADE, s/d).
\end{abstract}

Parece-me, portanto, mais vantajoso pensar em investigações sobre a roupa como método de estudo e interpretação histórica no lugar de engessá-las na classificação que se fez delas no momento em que foram criadas, desprezando o seu itinerário, suas mudanças físico-químicas e as implicações sobre os sentidos das roupas antigas na cultura contemporânea (ANDRADE, 2011, p. 1).

Aqui, a roupa é vista como fonte primária, o próprio objeto de estudo passível de variados caminhos de estudos e interpretações. As roupas são documentos essenciais para o estudo da história da indumentária e da moda, pois, como afirma Meneses (1983, p. 112), elas são "suporte material, físico, imediatamente concreto, da produção e reprodução da vida social". Analisar as roupas pelo viés da cultura material aproxima-se ao estudo arqueológico, no qual se almeja refletir sobre os costumes de certos povos a partir de objetos criados e consumidos pelos sujeitos. Pesquisas baseadas em objetos fornecem uma concepção inédita no desenvolvimento histórico e estético da moda (STEELE, 1998). A construção do conhecimento fundamentado na roupa como objeto de estudo "tem sido uma contribuição valiosa, enriquecedora e consistente à ciência e deve ser considerada no estudo histórico e contemporâneo da roupa" (GIES, 2008). Miller (2013, p. 64) afirma que "um estudo da indumentária não deve ser frio; ele precisa evocar o mundo tátil, emocional e íntimo dos sentimentos".

Porém, Nacif (2007, p. 9) e Benarush (2012, p. 114) dizem que este tipo de estudo ainda é pouco explorado pela historiografia contemporânea e que muitos pesquisadores negligenciam a importância da roupa como artefato da cultura material. Lou Taylor (2004) também explica que ainda existem barreiras no reconhecimento da importância cultural das roupas e que a maioria das pesquisas é ancorada em literatura primária e secundária, muitas vezes sem relação direta com pesquisas empíricas que insiram os artefatos no corpus da análise. Andrade complementa que “[...] limita-se a usar esses objetos como ilustração de texto ou decoração para a fala" (ANDRADE, s/d). Contudo, a existência de acervos e coleções públicas e privadas emerge como possibilidade de um contato mais aprofundado entre o pesquisador e o objeto-vestuário, que será utilizado como uma fonte primária, deixando de ser apenas uma ilustração. Podem, com isso, surgir caminhos para diferentes tipos de pesquisa, desde a materialidade até a imaterialidade que a roupa representa.

"Roupas são objetos que têm uma circulação social. Sua longevidade material, geralmente maior que a humana, possibilita-lhes transitar por diversos espaços e tempos" (ANDRADE, 2011, p. 1). Andrade (2016) e Benarush (2012) compartilham o mesmo pensamento quando afirmam que o estudo da moda como fenômeno cultural e categoria de patrimônio deve ser multidisciplinar e associar-se com áreas do conhecimento como a museologia, 
conservação têxtil, história, sociologia, psicologia, filosofia, economia, design e antropologia. Vale acrescentar que "[...] é verdade também que o campo da investigação da cultura material compreende um universo de múltiplos atravessamentos entre diferentes áreas e saberes" (SOARES; ANDRADE, 2017, p. 177).

Daniel Miller (2013), Judy Attfield (2000) e Jules Prown (1982) são os pioneiros nos estudos com o uso da cultura material como ferramenta, método, caminho indispensável para o entendimento real dos significados das roupas ${ }^{15}$. 0 livro Clothing as Material Culture, organizado por Daniel Miller e Susanne Kuchler (2005), apresenta diversos resultados de pesquisadores que trabalham com o viés da cultura material.

A presente pesquisa foi fundamentada na metodologia de Prown (1982) e Andrade (2008). Jules Prown trabalha na área de artes aplicadas, mas também participa de pesquisas nas áreas de ciências sociais e linguística; destaca-se dos demais estudos relacionados com arqueologia, pois aceita interposição subjetiva no processo de análise, que está diretamente ligado à relação sujeito (quem observa, manipula, analisa) x objeto da pesquisa. 0 professor da Universidade de Yale (EUA) desenvolveu um método especial para compreender o universo cultural por meio dos artefatos; tal metodologia não foi pensada exclusivamente para a moda, mas aplica-se facilmente às roupas. Sua metodologia é baseada na utilização dos objetos como pilares que conduzem a pesquisa e, assim, não serve apenas de ilustração para algum texto. A metodologia do autor norte-americano é descomplicada, priorizando inicialmente a observação dos aspectos físicos dos objetos, para depois investigar a história. Sua técnica abre novas possibilidades de investigação para a história da indumentária e da moda.

Para Prown (1982), a cultura material é um campo que se fundamenta no fato de que um objeto feito pelo homem possui indícios concretos da presença de um ser humano, além dos conhecimentos empregados nas técnicas de fabricação. 0 autor propõe um método de análise da cultura material, considerando a sua variedade como uma solução para se fundamentar a pesquisa, apresentando a classificação por categorias de análise da cultura material por etapas. São elas: 1) descrição - análise substancial, conteúdo e análise formal. No registro de evidências internas do objeto em si, restringe-se àquilo que se pode ver no objeto. Indica que se comece por uma descrição mais geral do objeto, passando sistematicamente para os detalhes. Nesta fase, é feita a representação do objeto, o desenho; 2) dedução - experiência sensorial, experiência intelectual e resposta emocional. É a interpretação da interação entre o objeto e o analista, o que é possível observar durante a primeira etapa; 3) especulação - formulação de hipóteses e programa de pesquisa, aliadas à análise das evidências externas (quantitativa, estilística e iconológica) ao objeto para testá-las e resolvê-las. Acontece na mente do analista, é a associação livre de ideias, percepções e imaginação.

Rita Morais de Andrade, brasileira e professora da Universidade Federal de Goiás, defendeu sua tese de doutorado em História sobre a biografia cultural de um vestido. Andrade

\footnotetext{
${ }^{15}$ Outros autores também vêm se destacando, são eles: Aileen Ribeiro, Chloe Colchester, Christopher Breward, Doris Langley e Anne Buck, Elizabeth Wilson, Susanne Kuchler, Talbot Hughes, Valerie Steele e, no Brasil, Rita de Andrade e Sheila Gies.
} 
(2008), apoiada na bibliografia para construção de sua tese (BARRETO, 1982/4; DURBIN; MORRIS; WILKINSON, 1990; PROWN, 1994; HORTA et al., 1999; TAYLOR, 2002), descreve cinco questões abordadas no estudo de um artefato têxtil: 1) observação das características físicas: observar as evidências internas do objeto por meio da percepção sensorial (o que se vê/o que se ouve); 2) descrição ou registro: desenhos, descrição verbal ou escrita, gráficos, fotografias, maquetes etc.; 3 ) identificação: exige conhecimento de materiais familiares ou não; 4) exploração ou especulação do problema: levantamento de hipóteses, discussões e questionamentos; 5) pesquisa em outras fontes e programas de pesquisa: desenvolvimento em um programa de estudo que partiu da análise de um objeto e expandiu-se pela formulação de hipóteses. 0 pesquisador deverá avançar para outras fontes tais como a escrita, a iconográfica, as fílmicas e entrevistas externas ao objeto estudado. Pode ainda trabalhar com comparação, ou seja, estudar peças semelhantes ou datadas da mesma época, para elucidar os aspectos observados e que se tornaram relevantes na problematização desenvolvida no processo de especulação.

A autora, pioneira no país em abordar esta relação, fala que é inadmissível abandonar o objeto e cometer o erro de deixar-se levar pela literatura e por generalizações históricas, utilizando a peça analisada apenas como ilustração do texto escrito.

\section{A biografia cultural de uma camisa}

Os indivíduos possuem um vínculo exclusivo com os objetos que guardam e estes tornam-se um tipo de registro documental, servem como uma ligação com o passado e os contadores de memórias. A vontade de se fazer preservar permite a guarda de um vestido, uma blusa, um casaco. Porém, devido à fragilidade da matéria-prima de que é composta a peça, muitas vezes as roupas são descartadas; mas,

[...] o que sobrevive normalmente é raro e deve-se investigar, quando possível, a biografia do artefato, considerando possíveis alterações no traje, a menos que a roupa tenha algum significado especial para uma família ou indivíduo, ela não é normalmente preservada e seu destino é quase sempre o descarte e o reuso (ANDRADE, 2016, p. 19).

Esta peça de roupa, confeccionada em um determinado período e contexto social e cultural, circula possibilitando que sua trajetória e biografia sejam pesquisadas, compreendendo que as características perceptíveis dos objetos podem revelar sua trajetória e historicidade, o que poderíamos chamar de uma biografia cultural desses objetos (ANDRADE, 2008, p. 25).

A biografia de um objeto é muito semelhante à biografia de uma pessoa, e se aproxima das correntes dos estudos culturais "especialmente no que diz respeito à descentralização, na interpretação histórica, do sujeito" (ANDRADE, 2011, p. 2). 0 objeto, então, torna-se uma fonte passível de identificação e de estudo das suas relações com os sujeitos e 
cotidianos. Kopytoff (2008, p. 93) explica que qualquer biografia é sempre construída sob a ótica do narrador: "De qualquer forma, a biografia (de pessoas ou de objetos) será sempre parcial, porque será escrita sob determinado ponto de vista - pessoal, familiar, profissional, econômico, etc".

Andrade (2008) explica que, no caso das roupas, existe uma biografia física - quanto ao material com que é confeccionada a peça -, uma biografia técnica - que refere-se às habilidades de quem fez e aos maquinários utilizados - e, ainda, uma biografia econômica, que diz respeito ao valor de mercado, custo de produção etc. Kopytoff (2008) utiliza o exemplo de um carro para falar em uma biografia social, o lugar das relações familiares, papel nas relações da família com a sociedade e/ou a forma de pertencimento a um determinado grupo social. Contudo, no presente artigo, optou-se, assim como Andrade (2008), por pesquisar a biografia cultural de uma camisa desde sua criação, passando pelo uso da peça por Antoninha Berchon, doação para a Ambar, divulgação em um editorial de moda para promoção do brechó beneficente, até vestir um novo corpo.

A camisa feminina ou chemise ${ }^{16}$ é uma peça de vestuário que historicamente esteve associada ao universo indumentário masculino. Para as mulheres esta vestimenta também se fazia presente, porém restrita ao conjunto de roupas íntimas ou roupas brancas. Entre os períodos Barroco e Rococó a camisa feminina atravessou algumas modificações em relação à sua forma e modelagem e, ainda, transitou do interno para o externo, ou seja, antes a peça figurava apenas na intimidade, separando o corpo do traje exterior, e depois passa a ser utilizada de modo aparente. A camisa feminina era também utilizada como forma de proteção física dos incômodos causados pelos corpetes e espartilhos e, ainda, por uma questão higiênica, visto que sua lavagem, como a de todas as outras roupas brancas, era feita com maior frequência e facilidade. Os trajes aparentes, aqui entendidos como a roupa externa, eram de modo geral confeccionados com tecidos mais pesados e adornados, não sendo higienizados com a mesma regularidade que as roupas brancas.

A visualidade da camisa no traje se dava se maneira diferente de acordo com o período histórico. Ora as mangas da camisa destacavam-se, ora a gola ou o peitilho eram vistos através do decote do traje externo. À guisa de exemplo, de acordo com Leventon (2009, p. 288), no século XVII as mangas da chemise eram reveladas por baixo do traje principal. Kohler (2001, p. 533-534) traz que entre 1850 e 1870 esta peça era frequentemente utilizada por baixo dos vestidos de lã e seda, sendo as mangas largas confeccionadas em cambraia e adornadas com bordados.

Entre o final do século XVIII e todo o século XIX a camisa foi ganhando uma maior notoriedade como peça aparente do guarda-roupa das mulheres. Stevenson (2012, p. 70) exemplifica que uma blusa de corte feminino com colarinho, por vezes utilizada com gravata, era o complemento para o traje de lazer inspirado na alfaiataria masculina. Apesar da

\footnotetext{
${ }^{16}$ Uma espécie de camisa de tecido leve, geralmente linho, usada por homens e mulheres como proteção da vestimenta de cima (em tecido mais nobre), dos suores do corpo. [...] A cor branca da chemise aparente sob os decotes simbolizava a "limpeza" do usuário (POLLINI, 2007, p. 25).
} 
chemise ser citada por diversos autores ${ }^{17}$ como peça fundamental do vestuário feminino, esta transição do interno para o externo não foi encontrada.

O objeto em questão neste artigo - a camisa - foi utilizado pela senhora Antoninha Berchon Sampaio ${ }^{18}$ em um evento organizado por sua filha Maria Rita Sampaio na estância São José, no município do Capão do Leão. Em uma recepção ao diretor de cinema Jayme Monjardim, durante as gravações do filme $O$ tempo e o vento em abril de 2012, Antoninha foi fotografada utilizando a peça aqui analisada (figura 1).

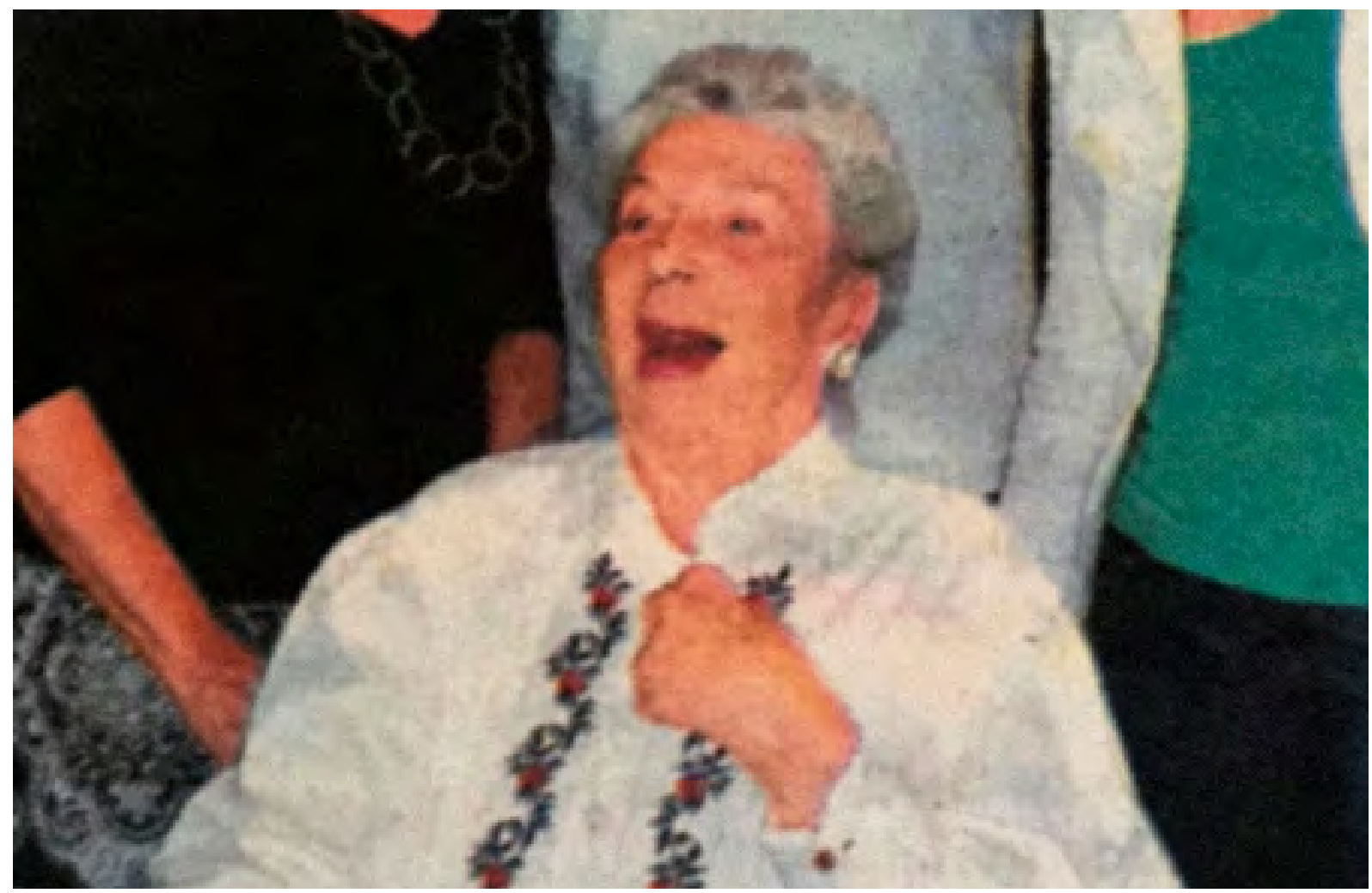

FONTE: JORNAL DIÁRIO POPULAR. Pelotas, 3 abr. 2012. Sociedade - Especial Marina Oliveira. Acervo dos autores.

\footnotetext{
${ }^{17}$ Kohler (2001), Sabino (2007), Leventon (2009), Stevenson (2012), Fogg (2013).

${ }^{18} \mathrm{~A}$ escolha da personagem principal da pesquisa se dá pelo fato de ter sido considerada uma figura de relevância dentro da sociedade de elite do Rio Grande do Sul. Segundo memórias autobiográficas (SAMPAI0, 2010), Antoninha Berchon nasceu em 28 de fevereiro de 1918, na Estância Santo Antônio, hoje município do Capão do Leão. Filha de Jayme de Carvalho e Vera Chaves des Essarts Carvalho, estudou no colégio Félix da Cunha em Pelotas e, com onze anos, foi para Paris com seu avô. De volta ao Brasil, morou no Rio de Janeiro, onde fez o curso de Assistente Social, casou com Luiz Raphael de Oliveira Sampaio e teve as filhas Maria Rita, Rosa May e Anna Luiza, além de nove netos. Nos anos 1970, ficou viúva e passou a se dedicar às atividades rurais, em uma época em que a presença feminina no campo era rara. "Quando viúva, vim como última da família tomar conta dos campos. Quis fazer faxina na casa da cidade onde agora morava titio Edmund, que ficara solteirão" (SAMPAI0, 2010, p. 37).
} 
Antoninha promoveu inúmeras atividades sociais e culturais em Pelotas; dentre elas estão as companhias de ballet cariocas que trouxe para o município, despertando, dessa forma, o gosto pela dança na cidade. Logo, a renda provinda dos espetáculos foi revertida para a Santa Casa de Pelotas. Mais tarde, preocupada com o mau estado dos prédios de Pelotas, trouxe novamente um grande espetáculo de ballet com bailarinos do Teatro Municipal, promovendo, assim, a reforma do casarão número 6 da Praça Coronel Pedro Osório. Com ajuda da filha Maria Rita, conseguiu articulações para o tombamento do Teatro Sete de Abril e de três prédios do centro histórico da cidade. Também por meio de suas relações sociais, conseguiu doações que hoje formam o acervo de vestuário do Museu da Baronesa. Este acervo está composto por peças de vestuário civil, litúrgico e militar, masculinas, femininas e infantis, que integram uma coleção de trajes do século XIX e princípios do século XX.

Para melhor analisar o objeto-vestuário aqui estudado, foi construída uma ficha de sistematização como parte do processo metodológico. Na ficha, constam descritores para o entendimento de aspectos materiais, técnicos e estilísticos dos trajes. Na figura 2, apresenta-se a ficha de sistematização da camisa analisada.

\section{FIGURA 2 - FICHA DE SISTEMATIZAÇÃO DA CAMISA PESQUISADA}

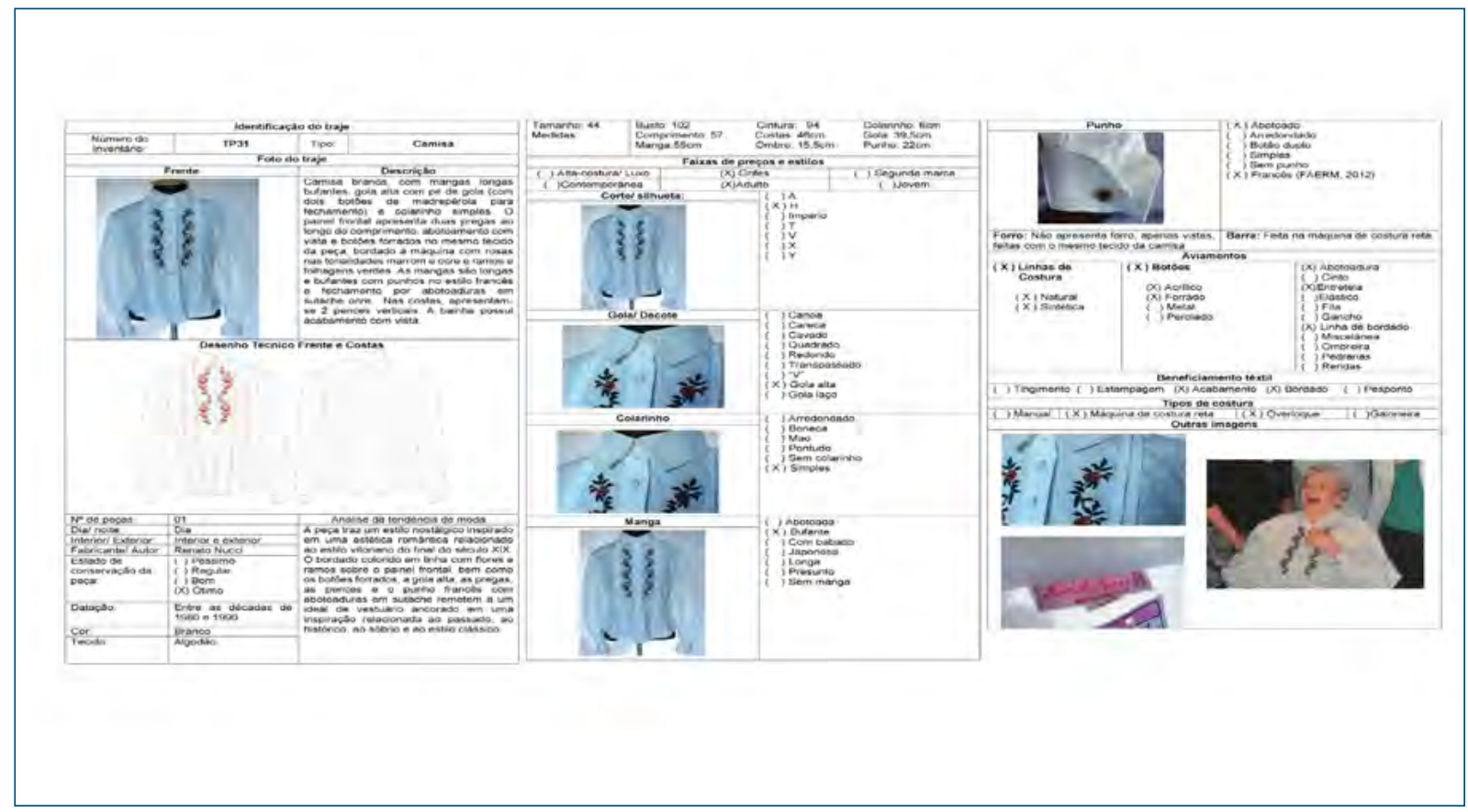

FONTE: construída pelos autores (2017).

Nesta ficha foram inseridas informações como descrições referentes à materialidade da peça (categoria, tamanho, cor, materiais, detalhes), desenho técnico frente e costas, análise da tendência de moda (aspectos estéticos referentes à criação da peça, estilo, técnicas empregadas), fabricante/marca, estado de conservação, componentes da roupa (silhueta, gola, colarinho, manga, punho), materiais (tecidos e aviamentos), tipos de costura (manual e/ou mecânica, tipo de máquina de costura) e imagens complementares. 
Através destas imagens complementares de Antoninha, pode-se observar que camisas eram recorrentes no seu guarda-roupa; prova disto é que, no acervo que foi doado para realização do brechó, dentre as 229 peças foram contabilizadas 30 camisas. A camisa apresenta a etiqueta da marca Renato Nucci - Paris. 0 estilista, que nasceu no Egito, mudou-se para Itália ainda criança e, aos 19 anos, foi morar em Paris, onde firmou sua marca especializada em camisas femininas em diferentes estilos. É considerado um dos primeiros designers inovadores responsáveis por revolucionar a moda feminina no início da década de 1970. Assim, ficou conhecido em toda a Europa como um ícone de moda por sua aparência e estilo de vanguarda. Os vestidos da marca foram usados pela aristocracia, celebridades e lançadores de tendência. Até onde se tem notícia ${ }^{19}$, conforme dados levantados em sites da internet, a marca chegou ao fim na década de 1990.

Não havendo a presença do sujeito de pesquisa para relatar a aquisição da peça analisada, uma das filhas de Antoninha informou em entrevista que esta peça fora adquirida na cidade de Montevidéu (Uruguai). Nas palavras de Maria Rita: "O que eu sei desta camisa foi que minha mãe comprou em Montevidéu para usar com uma saia bege que foi confeccionada pelo costureiro de sua preferência, Walter Otegui. Não sei que marca ela tem ${ }^{20 "}$.

Como já dito em outro momento, as peças de Antoninha foram doadas para a Ambar e, após serem analisadas e pesquisadas, foram encaminhadas para um brechó que arrecadou fundos para o Museu da Baronesa. Para a divulgação deste brechó, foi produzido um editorial de moda, no qual a camisa foi utilizada como figurino juntamente com outras peças. 0 conceito deste editorial esteve baseado na demonstração de peças consideradas vintage como itens relacionados a uma tendência de moda atual. Na figura 3 veem-se fotos nas quais aparece esta camisa.

FIGURA 3 - FOTOS DO EDITORIAL MEMÓRIA TRAJADA

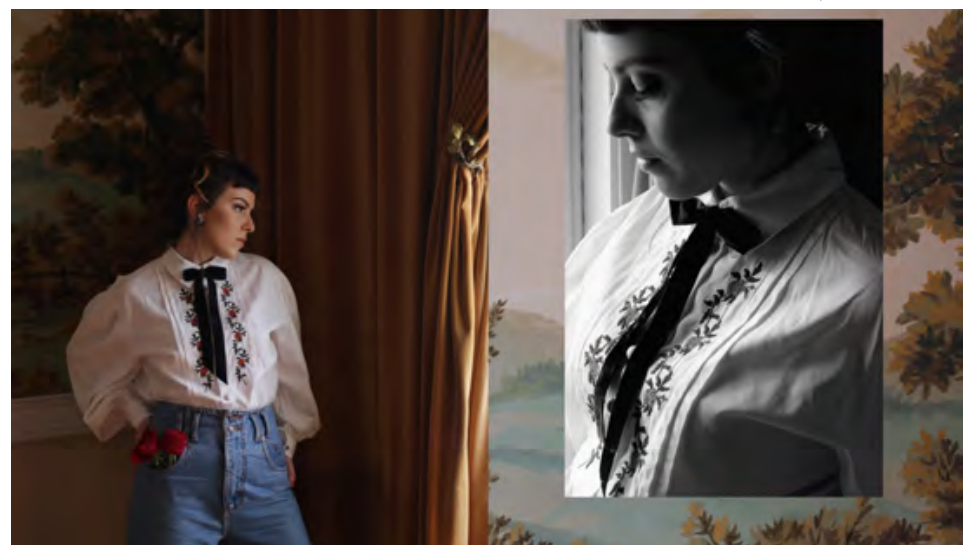

FONTE: GRILL, Nathalia. Modelo Dafne Monteiro no editorial “Memória Trajada”.

10 ago. 2017. Acervo dos autores.

\footnotetext{
${ }^{19}$ Estas informações foram retiradas e traduzidas pelos autores de uma entrevista concedida por Renato Nucci ao site Gossclub, pois não foram encontrados dados sobre o estilista e a marca na bibliografia impressa disponível. Disponível em: https://gossclub.com/business-man-turned-fashion-icon/. Acesso em: 12 jan. 2018.

${ }^{20}$ Entrevista concedida por SAMPAI0, Maria Rita. Entrevista I. [17 jan. 2018]. Entrevistadora: Frantieska Schneid. Pelotas, 2018. 1 arquivo.jpg.
} 
A camisa foi adquirida por Victoria Moreira, uma jovem de 25 anos, proprietária de um brechó, para uso pessoal. Logo após a aquisição da peça, Victoria postou em uma rede social fotos (figuras 4 e 5) trajando a peça. A nova proprietária pessoalmente contou aos autores que a motivação para a compra da roupa se deu após a divulgação do editorial e relatou ainda que já chegou ao brechó sabendo qual peça queria adquirir.

\section{FIGURAS 4 E 5 - VICTORIA MOREIRA TRAJANDO A CAMISA}
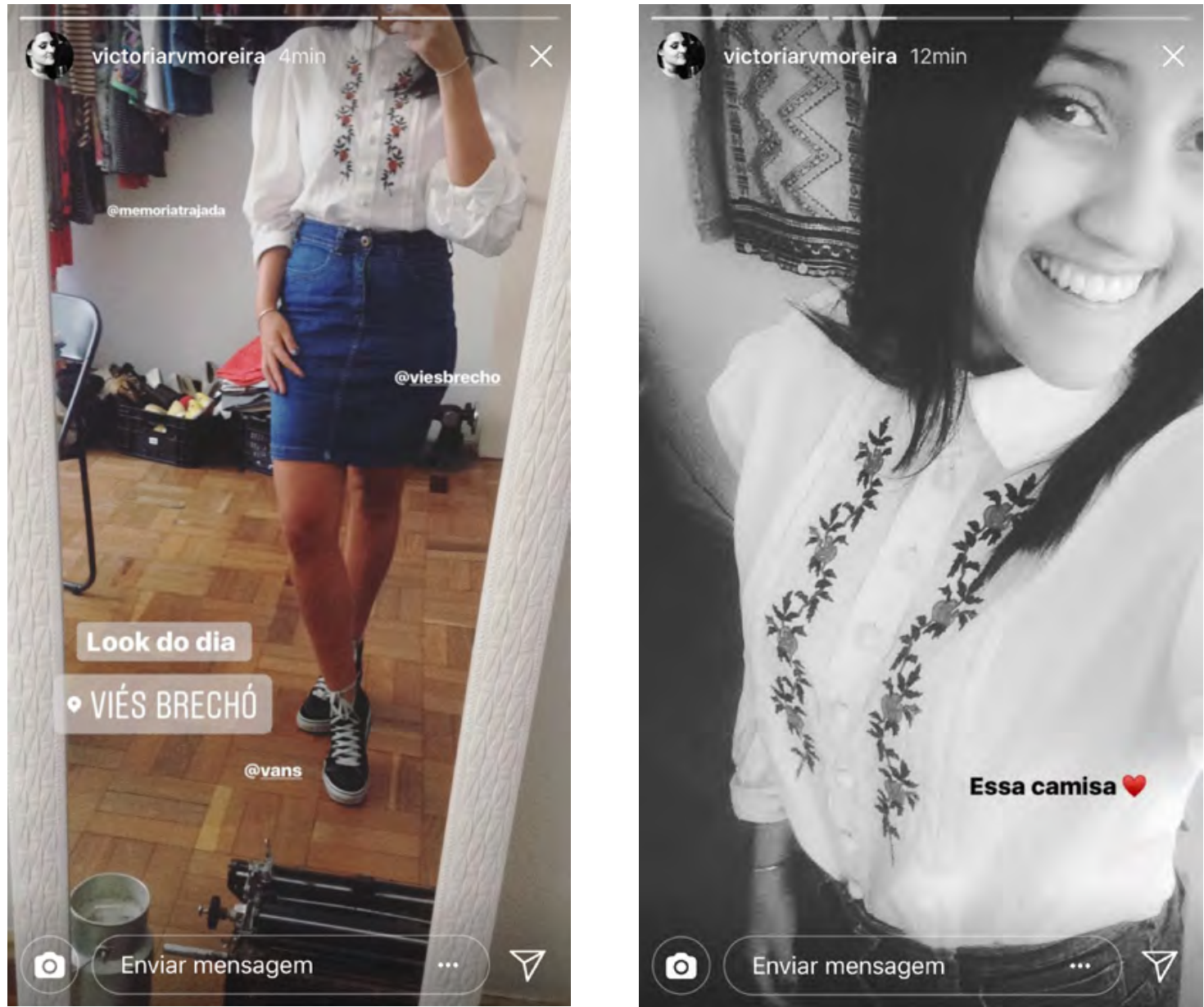

FONTE: MOREIRA, Victoria. Look do dia: viés brechó/Essa camisa. Pelotas, 4 set. 2017. Instagram: @victoriarvmoreira. Captura de tela realizada pelos autores.

Lurie (1997, p. 38-39) afirma que “Colocar as roupas de alguém é simbolicamente assumir sua personalidade. [...] Compartilhar roupas é sempre uma forte indicação de gostos, opiniões e, até mesmo, personalidades compartilhadas". Acerca disso, a atual proprietária da camisa também disse aos autores que, ao adquirir a peça tomou conhecimento sobre a biografia da senhora Antoninha Berchon Sampaio e que tal fato valora a camisa para além da sua utilidade e estilo vintage, ganhando significado afetivo e um novo estatuto para o traje. 


\section{Considerações finais}

O objetivo deste trabalho foi provocar reflexões resultantes da costura entre moda, memória, acervo e biografia cultural. Buscou-se neste artigo, que é o recorte do projeto de pesquisa "Memória Trajada", demonstrar as possibilidades metodológicas da roupa como um artefato cultural para um entendimento da circulação do traje por meio de diferentes sujeitos em seus corpos, imagens e espaços.

Através da análise realizada, pode-se perceber que a construção da aparência da senhora Antoninha Berchon esteve baseada em um estilo predominantemente clássico, sóbrio e romântico. Vários elementos visuais podem atestar a consolidação de uma permanência de estilo independente da passagem do tempo e das variações das tendências de moda. Determinados fatos ocorridos durante a vida da personagem central do estudo também poderiam corroborar a ideia já citada acerca de uma representação estética fundamentada na permanência. Isso delinear-se-ia pela sua posição econômica e sociocultural, seu período de vivência na cidade de Paris, seu papel de matriarca de uma família tradicional e grande produtora rural, reconhecida mundialmente.

A roupa, considerada como objeto pertencente à cultura material e imaterial, ora se apresenta fisicamente na esfera do artefato tangível, ora transita no campo do sensível, a partir da memória evocada pela imagem fotográfica ou narrativa. Almejou-se, no estudo, a construção de uma tessitura interdisciplinar, na qual se entrelaçaram diversos campos do saber e estes são fundamentais para entender as mensagens que os artefatos contam. É imprescindível o incentivo a projetos de pesquisa e trabalhos interdisciplinares que analisem acervos de vestuário como fontes de pesquisa para diversas áreas do conhecimento. Destaca-se também a relevância de trabalhar com fontes tridimensionais, nas quais o objeto investigado ganhará outras dimensões que não somente ilustrativas e/ou decorativas, mas que ampliam os olhares para um maior aprofundamento das possíveis faces de um objeto-vestuário.

Na intenção de traçar uma biografia cultural do objeto de vestuário pesquisado, foram utilizadas duas trajetórias: uma teórica, que usa a bibliografia para compreensão dos temas abordados, e outra prática, que constitui a análise do artefato em si. A união destas duas etapas levou os autores a pesquisar um objeto e a compreender as relações intrínsecas de um traje e seus desdobramentos em diferentes faces. Assim sendo, pode-se afirmar a importância da relação da roupa como objeto que carrega e narra memórias.

\section{Referências}

ANDRADE, Rita Moraes de. Por debaixo dos panos: cultura e materialidade de nossas roupas e tecidos. In: COLÓQUIO DE MODA, 2., 2006, Salvador. Anais do II Colóquio de Moda. Salvador: Abepem, 2006. Disponível em: http://www.coloquiomoda.com.br/anais/anais/2Coloquio-de-Moda_2006/artigos/100.pdf. Acesso em: 28 out. 2017. 
ANDRADE, Rita Moraes de. Boué Soeurs RG 7091: a biografia cultural de um vestido. 2008. 224 f. Tese (Doutorado em História) - Pontifícia Católica de São Paulo, São Paulo, 2008. Disponível em: https://tede2.pucsp.br/handle/handle/13076. Acesso em: 8 jul. 2019.

ANDRADE, Rita Moraes de. 0 caso do vestido e a biografia cultural das roupas. In: SIMPÓSIO NACIONAL DE HISTÓRIA, 26., 2011, São Paulo. Anais do XXVI Simpósio Nacional de História. São Paulo: Anpuh, 2011. Disponível em: https://anpuh.org.br/uploads/anaissimposios/pdf/2019-01/1548856705_84919e1ae0396fcdc6778e641af12dd7.pdf. Acesso em: 28 out. 2017.

ANDRADE, Rita Moraes de. Indumentária nos museus brasileiros: a invisibilidade das coleções. Revista Musas, n. 7, p. 10-31, 2016. Disponível em: https://www.museus.gov.br/ wp-content/uploads/2017/01/Musas-7.pdf. Acesso em: 28 out. 2017.

ANDRADE, Rita Moraes de. Cultura Material: o estudo da história da roupa/moda através da interpretação de objetos. Material didático do Programa de Pós-Graduação a distância Moda, consumo e cultura material, da Universidade Anhembi Morumbi. s/d.

ANDRZEJEWSKI, Luciana. A moda como despertar da memória. In: MERLO, Marcia (org.). Memórias e museus. São Paulo: Estação das Letras e Cores, 2015. p. 89-97.

ARTIÈRES, Phillipe. Arquivar a própria vida. Estudos Históricos, Rio de Janeiro, v. 11, n. 21, p. 9-34, 1998. Disponível em: https://www.marilia.unesp.br/Home/Pesquisa/cultgen/ arquivar_a_propria_vida.pdf. Acesso em: 28 out. 2017.

ATTFIELD, Judy. Wild Things: the material culture of everyday life. Oxford: Berg, 2000.

BARRETO, Maria de Lourdes Parreira Horta. Educação patrimonial e práticas centradas no objeto ligadas a teorias da organização do comportamento, 1982/84. Boletim Temático 1: Indumentária. Museu Paulista, Universidade de São Paulo, v. 1, n. 1, 1996.

BELLOTO, Heloisa Liberalli. Arquivos permanentes: tratamento documental. Rio de Janeiro: Fundação Getúlio Vargas, 2006.

BENARUSH, Michelle Kauffmann. A memória das roupas. dobra[s], v. 5, n. 12, p. 113-117, 2012. Disponível em: https://doi.org/10.26563/dobras.v5i12.121. Acesso em: 8 jul. 2019. 
BENARUSH, Michelle Kauffmann (org.). Termos básicos para catalogação de vestuário. Rio de Janeiro: Governo do Rio de Janeiro; Secretaria de Cultura; FUNARJ; Museus RJ, 2014.

BENARUSH, Michelle Kauffmann. Por uma museologia do vestuário: patrimônio, memória, cultura. In: MERLO, Marcia (org.). Memórias e museus. São Paulo: Estação das Letras e Cores, 2015. p. 99-111.

BOURDIEU, Pierre. Esboço de uma teoria da prática. In: ORTIZ, Renato (org.). Pierre Bourdieu: sociologia. Tradução Paula Montero e Alícia Auzmendí. São Paulo: Ática, 1983. p. $46-81$.

CALLIGARIS, Contardo. Verdades de autobiografias e diários íntimos. Revista Estudos Históricos, v. 11, n. 21, p. 43-58, 1998. Disponível em: http://bibliotecadigital.fgv.br/ojs/ index.php/reh/article/view/2071/1210. Acesso em: 28 out. 2017.

CUNHA, Maria Teresa Santos. Essa coisa deguardar... Homens deletras e acervos pessoais. História da Educação, ASPHE/FaE/UFPel, Pelotas, v. 12, n. 25, p. 109-130, maio/ago. 2008. Disponível em: https://dialnet.unirioja.es/descarga/articulo/4891583.pdf. Acesso em: 28 out. 2017.

DURBIN, Gail; MORRIS, Susan; WILKINSON, Sue. A teacher's guide to learning from objects. English: Heritage, 1990 (Apostila da exposição "Formas de Humanidade": Treinamento para Professores. São Paulo: MAE, Universidade de São Paulo, 1999).

FAERM, Steven. Curso de design de moda: princípios, prática e técnicas. Amadora, Portugal: Editorial Gustavo Gili, 2012.

FARACO, Camila. Morre em Pelotas Antoninha Berchon Sampaio. Gaúcha ZH, 5 out. 2014. Geral. Disponível em: https://gauchazh.clicrbs.com.br/geral/noticia/2014/10/morre-em-pelotasantoninha-berchon-sampaio-cj5vqhsas0phvxbj0y1p5u91l.html. Acesso em: 30 jan. 2018.

FOGG, Marnie. Tudo sobre moda. Tradução Débora Chaves, Fernanda Abreu, Ivo Korytowski. Rio de Janeiro: Sextante, 2013.

FRINGS, Gini Stephens. Moda: do conceito ao consumidor. 9. ed. Tradução Mariana Belloli. Porto Alegre: Bookman, 2012.

GIES, Sheila. Cultura material e design de moda contemporâneo: uma metodologia aplicada. In: COLÓQUIO DE MODA, 4., 2008, Novo Hamburgo. Anais do IV Colóquio de Moda. Novo Hamburgo: Abepem, 2008. Disponível em: http://www.coloquiomoda.com.br/anais/ Coloquio\%20de\%20Moda\%20-\%202008/42510.pdf. Acesso em: 28 out. 2017. 
GIES, Sheila. Design de Moda Brasileiro - uma abordagem da cultura material. Arcos Design, Rio de Janeiro, v. 7, n. 2, p. 113-127, dezembro de 2013. Disponível em: https://www.e-publicacoes. uerj.br/index.php/arcosdesign/article/download/.../9545. Acesso em: 28 out. 2017.

GLASSIE, Henry H. Material culture. Bloomington: Indiana University Press, 1999.

HORTA, Maria de Lourdes Parreiras et al. Guia básico de educação patrimonial. Brasília: Instituto do Patrimônio Histórico e Artístico Nacional, Museu Imperial, 1999. Disponível em: http://www.historia.seed.pr.gov.br/arquivos/File/sugestao_leitura/guia_educacao_ patrimonial.pdf. Acesso em: 28 out. 2017.

KOHLER, Carl. História do vestuário. Tradução Jefferson Luiz Camargo; revisão da tradução Silvana Vieira. São Paulo: Martins Fontes, 2001.

KOPYTOFF, Igor. A biografia cultural das coisas: a mercantilização como processo. In: APPADURAI, Arjun (org.). A vida social das coisas: as mercadorias sob uma perspectiva cultural. Niterói: EdUFF, 2008. p. 89-121.

KUCHLER, Susanne; MILLER, Daniel (ed.). Clothing as Material Culture. Oxford, New York: Berg, 2005.

JULIÃO, Leticia. Pesquisa histórica no museu. Cadernos de Diretrizes Museológicas. Brasília: Ministério da Cultura/IPHAN/DEMU; Belo Horizonte: Secretaria do Estado da Cultura/ Superintendência de Museus, 2006. p. 93-105. Disponível em: http://www.cultura. mg.gov.br/arquivos/Museus/File/caderno-diretrizes/cadernodiretrizes_quintaparte.pdf. Acesso em: 14 jul. 2019.

LEVENTON, Melissa (org.). História ilustrada do vestuário: um estudo da indumentária, do Egito antigo ao final do século XIX. Tradução Livia Almendary. São Paulo: Publifolha, 2009.

LURIE, Alison. A linguagem das roupas. Tradução Ana Luiza Dantas Borges. Rio de Janeiro: Rocco, 1997.

MACIEL, Ana Carolina de Moura Delfim. Personagens, seus objetos, suas imagens. Arcabouço material como evidência biográfica. Revista História Social, n. 24,p. 17-30, 2013. Disponível em: https://www.ifch.unicamp.br/ojs/index.php/rhs/article/view/1575/1081. Acesso em: 28 out. 2017.

MENESES, Ulpiano Toledo Bezerra. A cultura material no estudo das sociedades antigas. Revista de História, n. 115, p. 103-117, 1983. Disponível em: http://www.revistas.usp.br/ revhistoria/article/view/61796/64659. Acesso em: 28 out. 2017. 
MENESES, Ulpiano Toledo Bezerra. Memória e cultura material: documentos pessoais no espaço público. Estudos Históricos, v. 11, n. 21, p. 89-103, 1998. Disponível em: http:// bibliotecadigital.fgv.br/ojs/index.php/reh/article/view\%20File/2067/1206. Acesso em: 28 out. 2017.

MILLER, Daniel. Introduction. In: KUCHLER, Susanne; MILLER, Daniel (ed.). Clothing as Material Culture. Oxford, New York: Berg, 2005.

MILLER, Daniel. Trecos, troços e coisas: estudos antropológicos sobre a cultura material. Tradução Renato Aguiar. Rio de Janeiro: Zahar, 2013.

NACIF, Maria Cristina Volpi. O vestuário como princípio de leitura do mundo. In: SIMPÓSIO NACIONAL DE HISTÓRIA, 24., 2007, São Leopoldo. Anais [...]. São Leopoldo: Associação Nacional de História, 2007. Disponível em: http://snh2007.anpuh.org/resources/content/ anais/Maria\%20Cristina\%20V\%20Nacif.pdf. Acesso: 28 out. 2017.

PAULA, Teresa Cristina Toledo. A excepcional terra do pau-brasil: um país "sem tecidos". In: PAULA, Teresa Cristina Toledo (ed.). Tecidos e sua conservação no Brasil: museus e coleções. São Paulo: Museu Paulista da USP, 2006. p. 77-84.

PERROT, Michelle. Práticas da memória feminina. Revista Brasileira de História, São Paulo: Anpuh-Marco Zero, v. 9, n. 18, p. 9-18, 1989. Disponível em: https://www.anpuh.org/ arquivo/download?ID_ARQUIVO=3846. Acesso em: 28 out. 2017.

POLLAK, Michael. Memória e Identidade Social. Estudos Históricos, Rio de Janeiro, v. 5, n. 10, p. 200-212, 1992. Disponível em: http://www.pgedf.ufpr.br/memoria\%20e\%20 identidadesocial\%20A\%20capraro\%202.pdf. Acesso em: 28 out. 2017.

POLLINI, Denise. Breve história da moda. São Paulo: Editora Claridade, 2007. Coleção Saber de tudo.

POMIAN, Krzysztof. Coleção. In: Enciclopédia Einaudi, v. 1: Memória - História. Imprensa Nacional: Casa da Moeda, 1984. p. 51-86.

PROWN, Jules David. Mind in matter: an introduction to material theory and method. Winterthur Portfólio, Chicago, v. 17, n. 1, p. 1-19, Spring 1982. Disponível em: ciuhct.fc.ul. pt/textos/Prown_1982.pdf. Acesso em: 28 out. 2017.

PROWN, Jules David. Mind in matter: an introduction to material culture theory and method. In: PEARCE, Susan M. (ed.). Interpreting objects and collections. Londres: Routledge, 1994. p. 133-138. 
SABINO, Marco. Dicionário da Moda. Rio de Janeiro: Elsevier, 2007.

SAMPAIO, Antonia de Oliveira. Escrevendo a história de nossos antepassados. Pelotas: Editora Palloti, 2010.

SOARES, Kárita Garcia; ANDRADE, Rita Morais de. Estudar acervos e coleções de figurino no Brasil: alguns apontamentos. Anais Moda Documenta: Museu, Memória e Design, São Paulo, ano 4, n. 1, maio 2017. Disponível em: http://www.modadocumenta.com.br/ anais-2017/. Acesso em: 28 out. 2017.

SCHIFFER, Michael Brian. The material life of human beings: artifacts, behavior and communication. London and New York, Routledge, 1999.

SCHMITT, Juliana Luiza de Melo. Instâncias subjetivas das roupas: quando o vestuário conta histórias. Iara - Revista de Moda, Cultura e Arte, São Paulo, v. 2, n. 2, out./dez. 2009. Disponível em: http://www1.sp.senac.br/hotsites/blogs/revistaiara/wp-content/ uploads/2015/01/12_IARA_vol2_n2_Resenha.pdf. Acesso em: 28 out. 2017.

STEELE, Valerie. A museum of fashion is more than a clothes-bag. Fashion Theory: The journal of dress, body \& culture, New York: Berg, v. 2, n. 4, p. 327-335, 1998.

SIMILI, Ivana. Memórias trajadas: roupas e sentimentos no diário íntimo de uma prostituta. CLIO - Revista de Pesquisa Histórica, n. 30.2, 2012. Disponível em: https://periodicos.ufpe. br/revistas/revistaclio/article/view/24360/19732. Acesso em: 28 out. 2017.

STALLYBRASS, Peter. 0 casaco de Marx: roupas, memória, dor. Tradução Tomaz Tadeu. 4. ed. Belo Horizonte: Autêntica Editora, 2012.

STEVENSON, N. J. Cronologia da moda: de Maria Antonieta a Alexander McQueen. Tradução Maria Luiza X. de A. Borges. Rio de Janeiro: Zahar, 2012.

TAYLOR, Lou. Establishing dress history. Manchester, New York: Manchester University Press, 2004.

TAYLOR, Lou. The study of dress history. Manchester: Manchester University Press, 2002.

VIDAL, Laurent. Acervos pessoais e memória coletiva - alguns elementos de reflexão. Patrimônio e Memória, UNESP - FCLAs - CEDAP, v. 3, n. 1, p. 3-13, 2007. Disponível em: http://pem.assis.unesp.br/index.php/pem/article/view/1/452. Acesso em: 28 out. 2017. 
VOLPI, Maria Cristina. As roupas pelo avesso: cultura material e história social do vestuário. dObra[s], v. 7, n. 15, p. 70-78, 2014. Disponível em: https://doi.org/10.26563/dobras. v7i15.75. Acesso em: 8 jul. 2019.

VOLPI, Maria Cristina. Estilo urbano: modos de vestir na primeira metade do século XX no Rio de Janeiro. São Paulo: Estação das Letras e Cores, 2018.

\section{Agradecimentos}

O projeto "Memória Trajada" foi contemplado em um edital da Pró-Reitoria de Pesquisa (Propesp 03/2017) do Instituto Federal Sul-rio-grandense. Inclui-se aqui um agradecimento especial à iniciativa da instituição em contemplar um estudo sobre patrimônio, moda e memória. Políticas institucionais como esta contribuem para a produção do campo de pesquisa. Gostaríamos de destacar também a contribuição da colega mestranda Camila Rodrigues Oliveira, das bolsistas Fernanda Collares e Tuane Rodrigues e de todos os alunos voluntários que participaram do projeto de pesquisa "Memória Trajada". 